\title{
Implementation of Qualitative and Mixed Methods Researches
}

\author{
Ana M. Pinto-Llorente \\ Faculty of Education, \\ GRIAL Research Group, \\ University of Salamanca \\ 37008 Salamanca, Spain \\ ampintoll@usal.es
}

\author{
M. Cruz Sánchez-Gómez \\ Faculty of Education, \\ GRIAL Research Group, \\ University of Salamanca \\ 37008 Salamanca, Spain \\ mcsago@usal.es
}

\author{
António Pedro Dias da Costa \\ Education and psychology \\ Department \\ University of Aveiro \\ 3810-193 Aveiro, Portugal \\ apcosta@ua.pt
}

\begin{abstract}
The objective of the qualitative and quantitative integration in research designs is the reconciliation between paradigms and methods in research in social science. The objective to specify the general epistemological formulations on which qualitative methods are based in more precise and current methodological proposals, since we are in an exciting moment in the qualitative research in which it is appreciated a clear tendency in the use of a mixed methods research. During the Twentieth-First Century that have favoured the rise of mixed methods researches that enhance the mutual invigoration of the two types of methods, and facilitate the triangulation through operations. The aim of this track is to provide a space for reflection and put into practice the foundation, operationalization, and fields of application of qualitative and mixed methods researches.
\end{abstract}

\section{CCS CONCEPTS}

- Applied computing $\rightarrow$ Education $\rightarrow$ Learning management system engineering • Social and professional topics $\rightarrow$ Professional topics $\rightarrow$ Computing education $\rightarrow$ Adult education

\section{KEYWORDS}

Mixed methods research, quantitative research, qualitative research, triangulation, integration.

\section{ACM Reference format:}

A. M. Pinto-Llorente, M. C. Sánchez-Gómez and A. P. Dias Da Costa. 2018. Implementation of Quantitative and Mixed Methods Researches. In Proceedings of the 6th International Conference on Technological Ecosystems for Enhancing Multiculturality (TEEM 2018) (Salamanca, Spain, October 24-26, 2018), F. F. García-Peñalvo Ed. ACM, New York, NY, USA, 4 pages. https://doi.org/10.1145/3284179.3284271.

Permission to make digital or hard copies of all or part of this work for personal or classroom use is granted without fee provided that copies are not made or distributed for profit or commercial advantage and that copies bear this notice and the full citation on the first page. Copyrights for components of this work owned by others than the author(s) must be honored. Abstracting with credit is permitted. To copy otherwise, or republish, to post on servers or to redistribute to lists, requires prior specific permission and/or a fee. Request permissions from Permissions@acm.org.

TEEM'18, October 24-26, 2018, Salamanca, Spain

( 2018 Copyright is held by the owner/author(s). Publication rights licensed to ACM.

ACM ISBN 978-1-4503-6518-5/18/10...\$15.00

http://dx.doi.org/10.1145/3284179.3284271

\section{INTRODUCTION}

The objective of the qualitative and quantitative integration in research designs is the reconciliation between paradigms and methods in research in social science [1]. The aim is to specify the general epistemological formulations on which qualitative methods are based in more precise and current methodological proposals, since we are in an exciting moment in the qualitative research in which it is appreciated a clear tendency in the use of a mixed methods research [1].

The integration of both methods was already seen in the works developed by mathematicians and social researchers a few years ago which were based on the following propositions [2]:

- Social science researchers usually work with qualitative data, so they try to promote the development of appropriate mathematical patterns of analysis.

- Quality and quantity need each other if they do not want to lose their meaning. The meaning is diluted without the measure and the measure without meaning is only a mere number.

According to Flick [3, 4], qualitative and quantitative methods can be used together in the design of a research in the following modalities:

- Integration: continuous collection of both kinds of data.

- $\quad$ Sequencing: Qualitative and quantitative researches are placed in different stages of the same research process.

- Triangulation: It implies the combination of different qualitative methods and/or the combination of qualitative and quantitative methods. The two methodological perspectives receive the complementary compensation of the weak points they have when they are used in an individual way. However, both methods are autonomous, operating side by side, and none of them is better or preliminary. The point of encounter between them is the problem under study. 
There have been different key events during the TwentiethFirst Century that have favoured the rise of mixed methods researches:

- 2003: Special issue of the British Educational Research Journal about educational research in which four of the articles used mixed methods.

- 2007: The first issue of the Journal of Mixed Methods Research. A quarterly, international publication that focuses on empirical, methodological, and theoretical articles about mixed methods research across the social, behavioural, health, and human sciences.

- From 2008 to 2015: the publication of relevant works: Cámeron \& Quinn [5], Charmaz [6], Creswell y Plano Clark [7], Hernández et al [8], Morse [9], Morse \& Niehaus [10] and Tashakkori \& Teddlie $[11,12]$.

As Anguera [13] states the combined use of qualitative and quantitative methodology, since it is interested in the process and the result, enhances the mutual invigoration of the two types of methods, and facilitates the triangulation through operations. Delgado [14] emphasizes this idea and points out that it is not juxtaposition but a flexible combination of quantitative and qualitative components in stages of the research. She reinforces this idea and states that it is a combination of the formal rigour of the quantitative method and the creativity and plasticity of the qualitative one. Qualitative and quantitative data collection and analysis aim at integrating results and carrying out a combined discussion that allows making interferences to understand better and have a broader vision of the phenomenon.

Bryman [15], Delgado [14], Greene [16], Hernández et al [8] and Tashakkori \& Teddlie $[12,17]$ describe the advantages of mixed methods researches:

1. Triangulation: QUAN_QUAL corroboration.

2. Complementation: Clarification of the results of one method on the basis of the other.

3. Holistic vision: Complete and integral approach.

4. Development: The results of one method as a support of the processes of the other: sampling, collection, data analysis, new hypotheses, etc.

5. Initiation: Discovering contradictions, new frames of reference; modifying original approaches with the results of the other method.

6. Expansion: One method can expand the knowledge obtained by the other.

7. Compensation: The weaknesses of one method can be made up for the other.

8. Diversity: Different views of the problem.

9. Clarity: Displaying elements that are not detected by a single method.

10. Credibility and improvement: Reinforcing arguments, results and procedures from both methods.

\section{TRACK ORGANIZATION}

This section describes in further detail the seven contributions accepted to participate in this Conference track.

\subsection{Comprehensive analysis of the mass media visual component in the aspect of media aesthetics}

Irina Topchii [18] highlights how today, under the conditions of visual culture domination, the issues of particular text emotional perception by the audience, as well as questions of media aesthetics turn increasingly important. This paper uses one of the leading social and political Internet media, in the Russian language, as an empirical basis. This is the website Meduza, which is also presented in the most popular social network VKontakte, by RuNet. The thematic fields of media content of the public page are identified within the article. There is a classification of visual content as well as of the analysis of comments to the posts.

The author uses a set of different methods in the development of the research. These are: method of continuous sampling, content analysis and discourse analysis, and description and generalization. The complex nature of the methodology used in the study is aimed at deep and complex comprehension of the empirical material.

\subsection{Research Methods of the Musical Aesthetics Verbalization in the Context of Russian- Language Social Networks}

The second paper in the track by Maxim Demchuck [19] presents a study that tries to identify and discuss methods, relevant to the research design necessary to determine how musical aesthetics is verbalized in modern communication on the example of Russian-speaking social networks.

The author believes that it is within the framework of a mixed type study that one can determine the features of the music interaction, its verbal description and consciousness at the time of certain musical structures perception. The article discusses the possibility of an appropriate research constructing.

\subsection{Content analysis of visual elements in scientific journalism (on the example of the Website Postnauka)}

Svetlana Panyukova [20] presents a proposal devoted to the science journalism content analysis. This dynamic branch of modern media can be called topical since it helps readers to get the notion of unique scientific knowledge and to form a scientific worldview. That is especially up-to-date at advancement of technology, when various significant discoveries are constantly coming up.

Present article brings a question what visualization methods are the most frequently used by various scientific disciplines. The answer to the question raised is resolved through the content analysis of the PostNauka website content. 


\subsection{Applied mediaesthetic as a tool to analyze video contents from YouTube}

The fourth paper in the track by Arina Medvedeva [21] develops an approximate algorithm for the mediaesthetic analysis of video on YouTube. The research has also developed a classification of tools to examine the aesthetic impact of video clips on YouTube. This classification consists of five categories corresponding to aesthetic fields. The basis for the classification is Herbert Zettl's work "Applied Media Aesthetics".

The researcher suggests that such an algorithm and classification can help in further research of the video content on the YouTube site. A systematic approach to the analysis of videos by particular blogger contributes to the compilation and classification of the main aesthetic features of the channel.

\subsection{Virtual Reality versus Master Class. A comparative study}

Jiménez et al [22] carry out a research based on the implementation of technology based on virtual reality in a subject called "General Laboratory Techniques" of the 1st year of the VET Training Course entitled "Higher Technician in Pathological Anatomy and Cytodiagnosis" at the Universidad Europea de Madrid (UEM). The purpose of the study is to understand the impact on student learning and performance that including technology such as virtual reality in the classroom may have.

To this end they have opted for the use of a quasiexperimental design by means of two groups: a first experimental group that uses a virtual reality application, and a control group that receives a traditionally cut master class. After the quantitative and qualitative analysis carried out, the results show that there are statistically significant differences in the scores of the pretest and posttest tests in favor of the experimental group, that is, of the students who performed the activity with virtual reality.

They improved their performance against the students that used the traditional master class methodology. In addition, the results of the user experience survey, passed after using the app, were positive. In most of the cases, the average is above 4 over 5 for the degree of overall satisfaction shown by the students. Being very high/excellent for $60 \%$ of students and high for $40 \%$. Due to these factors, they conclude that the impact of virtual reality activities in the classroom is beneficial for the learning and the academic results of the students, in addition to their motivation.

\subsection{Applied mediaesthetic as a tool to analyze video contents from YouTube}

Simakova Svetlana [23] analyses the content of the AIF.ru media website. The content covers a tragic event, that stroke Kemerovo (Russia) in March 2018. That is a fire that burnt down a mall. The researcher applies the method of continuous sampling, the method of axial coding, and content analysis at different stages to analyze the AIF.ru content. It was concluded that photography is used for timely coverage of events.

The results have been achieved thanks to the method of continuous sampling and counting the number of visual content items by types. With the help of the method of axial coding, it is stated that there is a thematic (location, people) principle in grouping photos on the site. A completed content analysis made it possible to draw a conclusion that, first of all, the place of events and officials related to the incident are visualized. However, the personal grief is not displayed for the audience. As a rule, people are depicted as part of a single whole as crowds, as a large number of people, which symbolizes public tragedy in the pictures AIF.ru.

\subsection{A Research into the students' perceptions of technology and inclusive education}

The last paper in the track by Pinto-Llorente et al. [24] present a research whose aim is to explore students' perceptions about the effectiveness of technology in inclusive practices. Based on this purpose, researchers employ a mixed methods research, a combine of qualitative and quantitative methodology. 153 students of the last year of the Degree in Primary Education compose the population of the study. A total of 104 learners compose the quantitative sample and 57 participants the qualitative one. A questionnaire divided into three parts: sociodemographic details, Digital Competence, and Technology \& Inclusive Practices is the instrument used to collect quantitative data whereas individual semi-structured interviews are used to collect the qualitative ones.

The literature review and the finding of the research suggest the effectiveness of technology to design and implement inclusive practices, to adapt the teaching-learning process to pupils and contribute not only to the acquisition of different contents but also to stimulate learners' concentration on them. The findings point out the need to provide the adequate training to the university students during their Degree, and to review the Curriculum to avoid its rigidness and favor the implementation of inclusive practices.

\section{REFERENCES}

[1] M. Cruz Sánchez-Gómez. 2015. La dicotomía cualitativo-cuantitativo: posibilidades de integración y diseños mixtos. Campo Abierto. Revista De Educación, 1, 1, 11-30

[2] Eduardo Bericat. 1998. La integración de los métodos cuantitativo y cualitativo en la investigación social. Ariel. Barcelona.

[3] Uwe Flick. 2004. Introducción a la Investigación Cualitativa. Morata Madrid.

[4] Uwe Flick. 2014. La gestión de la calidad en la investigación cualitativa. Morata. Madrid.

[5] Kim. S. Cameron and Robert. E. Quinn. 2011. Diagnosing and changing organizational Culture: Based on the competing values framework. Jossey Bass. Reading, MA.

[6] Kathy Charmaz. 2013. Constructing grounded theory. SAGE. Thousand Oaks, CA.

[7] John. W. Creswell and Vicki L. Plano-Clark, V. L. 2006. Designing and conducting mixed methods research. SAGE. Thousand Oaks, CA.

[8] Roberto Hernández, Carlos Fernández and M. del Pilar Baptista. 2014 Metodología de la investigación. McGraw Hill, México.

[9] Janice M. Morse. 2012. Qualitative health research: Creating a new discipline. Left Coast Press. Walnut Creek, CA.

[10] Janice M. Morse and Linda Niehaus. 2010. Mixed method design: Principles and 
procedures. Left Coast Press. Walnut Creek, CA.

[11] Abbas Tashakkori and Charles Teddlie. 2003. The past and future of mixed methods research: From data triangulation to mixed model designs. In Handbook on mixed methods in the behavioral and social sciences, Abbas Tashakkori and Charles Teddlie, Eds. SAGE. Thousand Oaks, CA, 671-702.

[12] Abbas Tashakkori and Charles Teddlie. 2008. Introduction to mixed method and mixed model studies in the social and behavioral sciences. In The mixed methods reader, John. W. Creswell and Vicki L. Plano-Clark, Eds. SAGE. Thousand Oaks, CA, 7-26.

[13] M. Teresa Anguera. 2008. Metodologías cualitativas: características, procesos y aplicaciones. In Metodología en la investigación sobre discapacidad. Introducción al uso de las ecuaciones estructurales, Miguel A. Verdugo et al, Coords. Publicaciones INICO, Salamanca, 141-155.

[14] Carmen Delgado. 2014. Viajando a Ittaca por los mares cuantitativos, manual de ruta para investigar en grado y en postgrado. Amarú, Salamanca.

[15] Alan Bryman. Saul Becker and Joe Sempik. 2008. Quality criteria for quantitative, qualitative and mixed methods research: A view from socia policy. International fournal Social Research Methodology, 11, 4, 261-276. DOI: http://dx.doi.org/10.1080/13645570701401644.

[16] Jennifer C. Greene. 2008. Mixed methods in social inquiry. Jossey-Bass. San Francisco, CA.

[17] Abbas Tashakkori and Charles Teddlie. 2008. Quality of inferences in mixed methods research: Calling for an integrative framework. In Advances in mixed methods research, Manfred Max Bergman Ed. SAGE. Thousand Oaks, CA, 1-7.

[18] Irina Topchii. 2018. Comprehensive analysis of the mass media visual component in the aspect of media aesthetics. In Proceedings of the 6th International Conference on Technological Ecosystems for Enhancing Multiculturality (TEEM 2018) (Salamanca, Spain, October 24-26, 2018), F. 7 García-Peñalvo Ed. ACM, New York, NY, USA.

[19] Maxim Demchuk. 2018. Research Methods of the Musical Aesthetics Verbalization in the Context of Russian-Language Social Networks. In Proceedings of the 6th International Conference on Technological Ecosystems for Enhancing Multiculturality (TEEM 2018) (Salamanca, Spain, October 24-26,
2018), F. J. García-Peñalvo Ed. ACM, New York, NY, USA.

[20] Svetlana Panyukova. 2018. Content analysis of visual elements in scientifi journalism (on the example of the Website Postnauka). In Proceedings of the 6th International Conference on Technological Ecosystems for Enhancing Multiculturality (TEEM 2018) (Salamanca, Spain, October 24-26, 2018), F. F. García-Peñalvo Ed. ACM, New York, NY, USA.

[21] Arina Medvedeva. 2018. Applied mediaesthetic as a tool to analyze video contents from YouTube. In Proceedings of the 6th International Conference on Technological Ecosystems for Enhancing Multiculturality (TEEM 2018) (Salamanca, Spain, October 24-26, 2018), F. 7. García-Peñalvo Ed. ACM, New York, NY, USA.

[22] Eva Jiménez, Gonzalo Mariscal, Manuela Heredia and Guillermo Castilla. 2018 Virtual Reality versus Master Class. A comparative study. In Proceedings of the 6th International Conference on Technological Ecosystems for Enhancing Multiculturality (TEEM 2018) (Salamanca, Spain, October 24-26, 2018), F. F García-Peñalvo Ed. ACM, New York, NY, USA.

[23] Svetlana Simakova. 2018. Research methods of visual mass-media content. In Proceedings of the 6th International Conference on Technological Ecosystems for Enhancing Multiculturality (TEEM 2018) (Salamanca, Spain, October 24-26, 2018), F. 7. García-Peñalvo Ed. ACM, New York, NY, USA.

[24] Ana M. Pinto-Llorente, M. Cruz. Sánchez-Gómez, Óscar. J. Martín-Sánchez and M. Teresa del Moral-Marcos. 2018. A Research into the students' perceptions of technology and inclusive education. In Proceedings of the 6th International Conference on Technological Ecosystems for Enhancing Multiculturality (TEEM 2018) (Salamanca, Spain, October 24-26, 2018), F. F. García-Peñalvo Ed. ACM, New York, NY, USA. 